\title{
Formononetin protects against cisplatin-induced acute kidney injury through activation of the PPARa/Nrf2/HO-1/NQO1 pathway
}

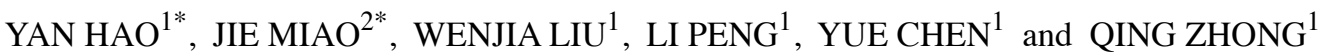 \\ ${ }^{1}$ Department of Nephrology, Zigong First People's Hospital; ${ }^{2}$ Department of Imaging Medicine, \\ Sichuan Vocational College of Health and Rehabilitation, Zigong, Sichuan 643000, P.R. China
}

Received January 16, 2020; Accepted May 22, 2020

DOI: $10.3892 / \mathrm{ijmm} .2020 .4805$

\begin{abstract}
Acute kidney injury (AKI) is characterized by an abrupt deterioration of renal function. Formononetin (FOR) protects against cisplatin (CIS)-induced AKI, and it has various potential pharmacological and biological effects, including anti-inflammatory, antioxidative and anti-apoptotic effects. The current study investigated the role of FOR in CIS-induced AKI. Rats were treated with CIS to establish an AKI model, followed by treatment with FOR. HK-2 cells were treated with CIS, FOR, GW6471 [a peroxisome proliferator-activated receptor $\alpha(\operatorname{PPAR} \alpha)$ antagonist], eupatilin (a PPAR $\alpha$ agonist) and nuclear factor erythroid 2-related factor 2 (Nrf2) small interfering RNA (siNrf2), and cell proliferation and apoptosis were determined by MTT and flow cytometry assays. The mRNA and proteins levels of PPAR $\alpha$, Nrf2, heme oxygenase-1 (HO-1) and $\mathrm{NAD}(\mathrm{P}) \mathrm{H}$ quinone dehydrogenase 1 (NQO1) were measured by reverse transcription-quantitative PCR and western blotting. The results demonstrated that FOR attenuated the histopathological changes, the levels of blood urea nitrogen, creatinine, TNF- $\alpha$ and IL- $1 \beta$, and the MDA content and MPO activity, whereas it enhanced CAT activity in the AKI rat model. Furthermore, FOR and eupatilin promoted cell viability and CAT activity, and increased the levels of PPAR $\alpha$,
\end{abstract}

Correspondence to: Dr Yan Hao, Department of Nephrology, Zigong First People's Hospital, No. 42, Shangyihao 1st Branch Road, Ziliujing, Zigong, Sichuan 643000, P.R. China

E-mail: hyan_haoyy@163.com

${ }^{*}$ Contributed equally

Abbreviations: FOR, formononetin; CIS, cisplatin; AKI, acute kidney injury; BUN, blood urea nitrogen; PPAR $\alpha$, peroxisome proliferator-activated receptor $\alpha$; Nrf2, nuclear factor erythroid 2-related factor 2; HO-1, heme oxygenase-1; NQO1, NAD(P)H quinone dehydrogenase 1; MDA, malondialdehyde; MPO, myeloperoxidase

Key words: formononetin, cisplatin, acute kidney injury, peroxisome proliferator-activated receptor $\alpha /$ nuclear factor erythroid 2-related factor $2 /$ heme oxygenase-1/NAD(P)H quinone dehydrogenase 1
Nrf2 and HO-1 and NQO1, but suppressed apoptosis and MPO activity, and reduced the levels of MDA, TNF- $\alpha$ and IL- $1 \beta$ in CIS-treated HK-2 cells. Notably, the aforementioned effects were reversed by GW6471 treatment or siNrf2 transfection. In conclusion, FOR protects against CIS-induced AKI via activation of the PPAR $\alpha / \mathrm{Nrf} 2 / \mathrm{HO}-1 / \mathrm{NQO} 1$ pathway.

\section{Introduction}

Acute kidney injury (AKI) is characterized by an abrupt deterioration of renal function and dysregulation of the release of fluids, electrolytes and waste into urine (1), and it will cause life-threatening complications (2). Due to a lack of available therapeutic options, AKI is prevented and the majority of patients with AKI receive only dialysis to replace kidney function (3).

Multiple pathological conditions, such as ischemiareperfusion, sepsis, trauma and release of nephrotoxic agents, as well as side-effects caused by therapeutic drugs are all responsible for the occurrence of AKI (4). Nephrotoxic AKI is caused by nephrotoxic agents, including drugs with therapeutic uses (5). Nephrotoxic AKI accounts for approximately 33\% of all AKI cases (6). As an effective chemotherapeutic agent, cisplatin (CIS) is commonly used for treating hematological and solid tumor malignancies (7). Nephrotoxicity is a principal side effect of CIS treatment (8). Proximal tubule cells can absorb CIS accumulated in all segments of the nephron, which causes severe injury (9). Thus, the efficacy of CIS is limited by its nephrotoxicity, and effective strategies or original drugs to protect patients against the nephrotoxic effect of CIS are urgently required.

Multiple natural products have been identified for the prevention and therapy of renal diseases (10). Formononetin (FOR) is a natural and bioactive isoflavone isolated from herbal medicines, such as Trifolium pretense, Astragalus membranaceus and Pueraria lobate (11). It has recently been reported that FOR prevents CIS-induced AKI (12); however, to the best of our knowledge, the underlying molecular mechanism of FOR in preventing CIS-induced AKI is not clearly understood. Evidence has increasingly demonstrated that CIS-mediated nephrotoxicity is caused by a number of molecular pathways, such as oxidative stress, apoptosis and 
inflammatory reactions $(8,13)$. Malondialdehyde (MDA) is an indicator of lipid peroxidation, catalase (CAT) catalyzes the decomposition of hydrogen peroxide into oxygen and water, and myeloperoxidase (MPO) serves as an oxidative marker and an indicator of neutrophil infiltration into kidneys (14). A previous study reported that FOR has various potential pharmacological and biological effects, such as anti-inflammatory (15), antioxidative (16) and anti-apoptotic effects (17). Thus, the present study investigated the effects and protective mechanism of FOR by examining oxidative stress, apoptosis and inflammatory pathways in CIS-induced AKI rats and cells.

It has been demonstrated that FOR protects against rhabdomyolysis-induced AKI (18). FOR prevents against CIS-induced AKI by targeting organic cation transporter 2 and P53; however, to the best of our knowledge, the exact effect and potential mechanism underlying the effects of FOR in CIS-induced AKI remain unclear. Thus, the present study determined the target gene of FOR in CIS-induced AKI. Peroxisome proliferator-activated receptor $\alpha(\operatorname{PPAR} \alpha)$ is a member of the steroid hormone receptor superfamily (18). Gonzalez-Manan et al (19) reported that in C57BL/6J mice fed a high-fat diet, the activation of PPAR $\alpha$ is involved in the inhibition of oxidative stress and inflammatory reaction. Wang et al (20) demonstrated that activation of PPAR $\alpha$ inhibits apoptosis of vascular adventitial fibroblasts. Furthermore, FOR is involved in the regulation of PPAR $\alpha$ in ameliorating cholestasis (21).

Previously, it has been revealed that activation of nuclear factor erythroid 2-related factor 2 (Nrf2) improves renal function (22). Upregulation of the Nrf2-mediated signaling pathway protects against CIS-induced renal injury (23). In addition, when cells undergo chemical/oxidative stress, Nrf2 accumulates within the nuclei, in which Nrf2 activates the expressions of antioxidant response element (ARE)-driven genes, such as heme oxygenase-1 (HO-1) and NAD(P)H quinone dehydrogenase 1 (NQO1) (24). The Nrf2/HO-1 signaling pathway protects cells from CIS-induced nephrotoxicity (25).

The current study investigated the protective effects of FOR on CIS-induced AKI and the potential mechanisms, such as via the Nrf2 pathway. It was identified that FOR could serve as a preventative drug in treating CIS-induced AKI.

\section{Materials and methods}

Ethics statement. Animal experiments were performed in accordance with the guidelines of the China Council on Animal Care and Use. The use of the animals was approved by the Ethical Committee of Experimental Animals of Zigong First People's Hospital (approval no. ZFPH201904223), and the animal experiments were performed at Zigong First People's Hospital (Zigong, China). All possible efforts were made to minimize pain and discomfort caused to the animals.

Animals and drug treatments. A total of 24 male Wistar rats (body weight, 220-250 g; age, 9-10 weeks) were purchased from the Experimental Animal Center of Zigong First People's Hospital (Zigong, China). All rats were housed in standard cages with a room temperature of $22^{\circ} \mathrm{C}$ and humidity of $55 \%$, under a normal 12/12 h light/dark cycle, and provided food and water ad libitum. The rats were divided into four different treatment groups, as follows: i) Control group; ii) CIS group; iii) FOR group; and iv) CIS + FOR group, with 6 rats in each group. FOR was purchased from Dalian Meilun Biotech Co., Ltd.

In the control group, vehicle $(75 \mathrm{mg} / \mathrm{kg} 10 \%$ hydroxypropyl $\beta$-cyclodextrin (Sigma-Aldrich; Merck KGaA) in $500 \mathrm{mM}$ phosphate buffer, $\mathrm{pH}$ 7.0) was administrated into the rats by oral gavage once a day for 5 days. On days 3 and 4, the rats were also intraperitoneally injected with normal saline $4 \mathrm{~h}$ after vehicle treatment.

The CIS group was treated as the control group, except that on days 3 and 4 , the rats were intraperitoneally injected with CIS (12 mg/kg; Sigma-Aldrich; Merck KGaA) 4 h after vehicle treatment instead of with phosphate buffer. The concentration of CIS to use was determined as previously described (12).

In the FOR group, FOR (75 mg/kg), which has been reported to induce the strongest inhibition of CIS-induced nephrotoxicity previously (12), was administrated into the rats by oral gavage once a day for 5 days. On days 3 and 4, the rats were intraperitoneally injected with physiological saline $4 \mathrm{~h}$ after FOR treatment.

In the CIS + FOR group, FOR $(75 \mathrm{mg} / \mathrm{kg}$ ) was administrated into the rats by oral gavage once a day for 5 days. On days 3 and 4, the rats were intraperitoneally injected with CIS $(12 \mathrm{mg} / \mathrm{kg}) 4 \mathrm{~h}$ after FOR treatment.

On day 5, $4 \mathrm{~h}$ after treatment, all the rats were sacrificed with pentobarbital sodium $(165 \mathrm{mg} / \mathrm{kg}$, i.p.) and the heartbeat was checked. The both kidneys and blood $(1 \mathrm{ml}$ from the tail vein) were collected, and plasma was separated from the blood. The renal tissue samples were immediately fixed with $10 \%$ formalin at room temperature for $24 \mathrm{~h}$, paraffin-embedded, sectioned into $5 \mu \mathrm{m}$-thick slides, and then stained with hematoxylin and eosin ( $\mathrm{H} \& \mathrm{E})$. In addition, the renal tissue homogenate was centrifuged at $3,500 \times \mathrm{g}$ for $10 \mathrm{~min}$ at $4^{\circ} \mathrm{C}$, and MDA content, and CAT and MPO activities were detected using the supernatant. Levels of blood urea nitrogen (BUN), creatinine, TNF- $\alpha$ and IL-1 $\beta$ were also detected in the rat plasma.

Renal histological studies. Paraffin-embedded kidney sections were stained with H\&E. Histological changes, such as degree of tubular injury, were visualized and photographs were obtained using a light microscope (magnification, $\mathrm{x} 200$ ). In detail, following dewaxing, the section was stained with hematoxylin solution (cat. no. HHS16; Sigma-Aldrich; Merck $\mathrm{KGaA}$ ) at room temperature for $10 \mathrm{~min}$. Subsequently, the section were washed and stained with eosin solution (cat. no. 318906; Sigma-Aldrich; Merck $\mathrm{KGaA}$ ) at room temperature for $5 \mathrm{~min}$. A semi-quantitative pathological grading method was used to assess the degree of tubular injury, including tubular dilation, necrosis and cell membrane bleb formation (26). Two pathologists, who were blinded to the treatment, independently evaluated the histopathological changes of each image using a light microscope (magnification, x200). A total of 24 images of one section were used to calculate the pathological changes (\%) according to the injury score (0 for $0 \%, 1$ for $<5 \%, 2$ for $5-24 \%, 3$ for $25-74 \%, 4$ for $75-100 \%$ ), which was based on a system previously reported (26). 
Table I. Primary antibodies used for western blotting.

\begin{tabular}{|c|c|c|c|c|}
\hline Target protein & Antibody & Cat. no. & Supplier & Working dilution \\
\hline $\operatorname{PPAR} \alpha$ & Rabbit anti-PPAR $\alpha$ antibody & ab24509 & Abcam & $1: 100$ \\
\hline Nrf2 & Mouse anti-Nrf2 antibody & ab89443 & Abcam & $1: 1,000$ \\
\hline HO-1 & Rabbit anti-HO-1 antibody & ab13243 & Abcam & $1: 2,000$ \\
\hline NQO1 & Mouse anti-NQO1 antibody & ab28947 & Abcam & $1: 1,000$ \\
\hline$\beta$-actin & Mouse anti- $\beta$-actin antibody & ab8226 & Abcam & $1: 1,000$ \\
\hline
\end{tabular}

PPAR $\alpha$, peroxisome proliferator-activated receptor $\alpha$; Nrf2, nuclear factor erythroid 2-related factor 2; HO-1, heme oxygenase-1; NQO1, $\mathrm{NAD}(\mathrm{P}) \mathrm{H}$ quinone dehydrogenase 1.

Biochemical measurements. The levels of BUN and creatinine in rat plasma were determined using a Urea assay kit (cat. no. C013-2-1) and Creatinine assay kit (cat. no. C011-1-1), respectively. Kidney tissues were rinsed in $100 \mathrm{mg} / \mathrm{ml}$ normal saline, then weighed and homogenized. MDA content and activities of CAT and MPO in the homogenate supernatant were determined. MDA in the supernatant of homogenized renal tissues from rats was measured using a MDA assay kit (cat. no. A003-1-2). The CAT enzymatic activity was measured using the CAT assay kit (cat. no. A007-1-1). The activity of MPO was measured by MPO assay kit (cat. no. A044-1-1). All kits were purchased from Nanjing Bioengineering Institute Co., Ltd and used according to the manufacturer's protocols. The levels of TNF- $\alpha$ and IL-1 $\beta$ in the rat plasma were measured using a Rat TNF- $\alpha$ ELISA kit (cat. no. SEKR-0009; Beijing Solarbio Science \& Technology Co., Ltd.) and a Rat IL-1 $\beta$ ELISA kit (cat. no. SEKR-0002; Beijing Solarbio Science \& Technology Co., Ltd.).

Western blotting. Lysates from renal tissues of the Wistar rats and HK-2 cells were lysed with RIPA lysis buffer (Cell Signaling Technology, Inc.) to isolate proteins, and PPAR $\alpha$, Nrf2, HO-1 and NQO1 proteins were analyzed. Briefly, total proteins of renal tissues were extracted using RIPA buffer (cat. no. R0010; Beijing Solarbio Science \& Technology Co., Ltd.) with a complete protease inhibitor cocktail (cat. no. 539133; Merck KGaA) on ice for $30 \mathrm{~min}$. Subsequently, the supernatant was collected, and the protein concentration was determined using a BCA protein assay kit (cat. no. PC0020; Beijing Solarbio Science \& Technology Co., Ltd.). Proteins (30 $\mu \mathrm{g} /$ lane) were then separated by $12 \%$ SDS-PAGE (cat. no. P0012A; Beyotime Institute of Biotechnology) and transferred onto PVDF membranes (cat. no. IPVH00010; EMD Millipore). The membranes were blocked with $5 \%(\mathrm{w} / \mathrm{v})$ non-fat milk in Tris-buffered saline containing $0.5 \%$ Tween-20 (w/v) at $37^{\circ} \mathrm{C}$ for $1 \mathrm{~h}$. Next, the membranes were probed with the specific primary antibodies listed in Table I at $4^{\circ} \mathrm{C}$ overnight, and then washed with TBS containing $0.1 \%$ Tween-20. $\beta$-actin was used as the reference gene. The membranes were then incubated with HRP-conjugated goat anti-mouse secondary antibody (1:2,000; cat. no. ab205719; Abcam) and HRP-conjugated goat anti-rabbit secondary antibody (1:2,000; cat. no. ab205718; Abcam) at $37^{\circ} \mathrm{C}$ for $1 \mathrm{~h}$. After washing the membranes three
Table II. Primer sequences used for reverse transcriptionquantitative PCR analysis of rat samples.

\begin{tabular}{|c|c|c|}
\hline Gene & & Primer sequence $\left(5^{\prime}-3^{\prime}\right)$ \\
\hline \multirow[t]{2}{*}{$\operatorname{PPAR} \alpha$} & Forward & AGAGCCCCATCTGTCCTCTC \\
\hline & Reverse & ACTGGTAGTCTGCAAAACCAAA \\
\hline \multirow[t]{2}{*}{ Nrf2 } & Forward & TCTTGGAGTAAGTCGAGAAGTGT \\
\hline & Reverse & GTTGAAACTGAGCGAAAAAGGC \\
\hline \multirow[t]{2}{*}{$\mathrm{HO}-1$} & Forward & AGGTACACATCCAAGCCGAGA \\
\hline & Reverse & CATCACCAGCTTAAAGCCTTCT \\
\hline \multirow[t]{2}{*}{ NQO1 } & Forward & AGGATGGGAGGTACTCGAATC \\
\hline & Reverse & AGGCGTCCTTCCTTATATGCTA \\
\hline \multirow[t]{2}{*}{$\beta$-actin } & Forward & GGCTGTATTCCCCTCCATCG \\
\hline & Reverse & CCAGTTGGTAACAATGCCATGT \\
\hline
\end{tabular}

PPAR $\alpha$, peroxisome proliferator-activated receptor $\alpha$; Nrf2, nuclear factor erythroid 2-related factor 2; HO-1, heme oxygenase-1; NQO1, $\mathrm{NAD}(\mathrm{P}) \mathrm{H}$ quinone dehydrogenase 1 .

times at an interval of $10 \mathrm{~min}$, the signals were visualized using ECL detection kit (Promega Corporation) and Protein expression levels were quantified using ImageJ software (version 1.8.0; National Institutes of Health) and normalized to that of $\beta$-actin.

Reverse transcription-quantitative PCR (RT-qPCR). Total RNA was isolated from tissue and cells using TRIzol reagent (cat. no. 15596018, Invitrogen; Thermo Fisher Scientific, Inc.), and the mRNA expression levels of PPAR $\alpha, \mathrm{Nrf} 2, \mathrm{HO}-1$ and NQO1 were determined. PrimeScript ${ }^{\mathrm{TM}}$ RT Master mix was used for RT (cat. no. RR036B; Takara Bio, Inc.) and incubated at $37^{\circ} \mathrm{C}$ for $15 \mathrm{~min}$, followed by incubation at $85^{\circ} \mathrm{C}$ for $5 \mathrm{sec}$. qPCR was performed with a 7300 real-time PCR system (Applied Biosystems; Thermo Fisher Scientific, Inc.) using TB Green ${ }^{\circledR}$ Premix Ex Taq ${ }^{\text {TM }}$ II (cat. no. RR820Q; Takara Bio, Inc.). The thermocycling conditions were as follows: Incubation at $95^{\circ} \mathrm{C}$ for $30 \mathrm{~min}$, followed by amplification at $95^{\circ} \mathrm{C}$ for $5 \mathrm{sec}$ and $60^{\circ} \mathrm{C}$ for $34 \mathrm{sec}$ for a total of 40 cycles, $72^{\circ} \mathrm{C}$ for $30 \mathrm{sec}$, with a final extension at $72^{\circ} \mathrm{C}$ for $90 \mathrm{sec}$. The expression levels of genes were normalized to that of $\beta$-actin using the $2^{-\Delta \Delta \mathrm{Cq}}$ method (27). The sequences of primers used are presented in Table II and III. 
Table III. Primer sequences used for reverse transcriptionquantitative PCR analysis of HK-2 cells.

\begin{tabular}{|c|c|c|}
\hline Gene & & Primer sequence $\left(5^{\prime}-3^{\prime}\right)$ \\
\hline \multirow[t]{2}{*}{ PPAR $\alpha$} & Forward & ATGGTGGACACGGAAAGCC \\
\hline & Reverse & CGATGGATTGCGAAATCTCTTGG \\
\hline \multirow[t]{2}{*}{ Nrf2 } & Forward & TCAGCGACGGAAAGAGTATGA \\
\hline & Reverse & CCACTGGTTTCTGACTGGATGT \\
\hline \multirow[t]{2}{*}{ HO-1 } & Forward & AAGACTGCGTTCCTGCTCAAC \\
\hline & Reverse & AAAGCCCTACAGCAACTGTCG \\
\hline \multirow[t]{2}{*}{ NQO1 } & Forward & GAAGAGCACTGATCGTACTGGC \\
\hline & Reverse & GGATACTGAAAGTTCGCAGGG \\
\hline \multirow[t]{2}{*}{$\beta$-actin } & Forward & CATGTACGTTGCTATCCAGGC \\
\hline & Reverse & CTCCTTAATGTCACGCACGAT \\
\hline
\end{tabular}

PPAR $\alpha$, peroxisome proliferator-activated receptor $\alpha$; Nrf2, nuclear factor erythroid 2-related factor 2; HO-1, heme oxygenase-1; NQO1, $\mathrm{NAD}(\mathrm{P}) \mathrm{H}$ quinone dehydrogenase 1.

Cell culture. HK-2 (human kidney proximal tubule) cells were purchased from the American Type Culture Collection and incubated in DMEM/F12 (cat. no. BNCC342221; BeNa Culture Collection) containing $10 \%$ fetal bovine serum (cat. no. 11011-8611; Beijing Solarbio Science \& Technology Co., Ltd.) and 1\% Penicillin-Streptomycin Liquid (cat. no. P1400; Beijing Solarbio Science \& Technology Co., Ltd.) with $5 \% \mathrm{CO}_{2}$ at $37^{\circ} \mathrm{C}$.

To investigate the role of PPAR $\alpha$ in FOR preventing CIS-induced injury of HK-2 cells, GW6471 (cat. no. G5045; Sigma-Aldrich; Merck KGaA), which is a selective PPARa antagonist, was used to inhibit PPAR $\alpha$ in HK-2 cells. The cells were pre-treated with normal saline or $25 \mu \mathrm{M} \mathrm{GW6471} \mathrm{for}$ $30 \mathrm{~min}$, and then cultured with 10 or $25 \mu \mathrm{M}$ FOR for $2 \mathrm{~h}$ at room temperature. Next, the cells were treated with $25 \mu \mathrm{M}$ CIS for $24 \mathrm{~h}$. The treatments for different cell groups were as follows: i) Control group, cells treated with PBS; ii) CIS group, cells treated with $25 \mu \mathrm{M}$ CIS; iii) CIS + FOR-L group, cells treated with $25 \mu \mathrm{M}$ CIS and $10 \mu \mathrm{M}$ FOR; iv) CIS + FOR-H group, cells treated with $25 \mu \mathrm{M}$ CIS and $25 \mu \mathrm{M}$ FOR; and v) CIS + FOR-H + GW6471 group, cells treated with $25 \mu \mathrm{M}$ CIS, $25 \mu \mathrm{M}$ FOR and $5 \mu \mathrm{M}$ GW6471.

Transfection. The expression of Nrf2 was inhibited using Nrf2 small interfering RNA (siRNA; siNrf2) to further investigate the potential mechanism of PPAR $\alpha$ in FOR prevention of HK-2 cells treated with CIS. The siNrf2 (5'-GACATGGAT TTGATTGACATACT-3') and siRNA negative control (siNC; 5'-CACTTGAATCCGACGGATTTGCA-3') were purchased from Guangzhou RiboBio Co., Ltd. HK-2 cells transfected with siNC or siNrf2 served as the negative control group or siNrf2 group, respectively. The cells, cultured in 6-well culture plates in serum-free OPTI-MEM medium (Gibco; Thermo Fisher Scientific, Inc.), were transfected with $100 \mathrm{nM}$ siNC or $100 \mathrm{nM}$ siNrf2 using Lipofectamine (Invitrogen; Thermo Fisher Scientific, Inc.) for $24 \mathrm{~h}$. The next day, the cells were incubated in fresh medium for a further $48 \mathrm{~h}$, and then subjected to the following treatments.
Following cell transfection with siNrf2, the cells were pre-treated with $50 \mu \mathrm{g} / \mathrm{ml}$ eupatilin (PPAR $\alpha$ agonist; cat. no. HY-N0783; MedChemExpress) for $24 \mathrm{~h}$, and then cultured with $25 \mu \mathrm{M}$ FOR for $2 \mathrm{~h}$ at room temperature. Eupatilin was used to treat the cells for the purpose of comparing its effect with that of FOX on CIS injury. Subsequently, the cells were cultured with $25 \mu \mathrm{M}$ CIS for $24 \mathrm{~h}$. The treatments for different cell groups were as follows: i) siNC, transfection with siNC only; ii) siNC + CIS, siNC transfection and CIS $(25 \mu \mathrm{M})$ treatment; iii) CIS + eupatillin + siNC, siNC transfection with CIS $(25 \mu \mathrm{M})$ and eupatillin $(50 \mu \mathrm{g} / \mathrm{ml})$ treatment; iv) CIS + eupatillin + siNrf2, siNrf2 transfection with CIS $(25 \mu \mathrm{M})$ and eupatillin $(50 \mu \mathrm{g} / \mathrm{ml})$ treatment; v) CIS + FOR-H + siNC, siNC transfection with CIS $(25 \mu \mathrm{M})$ and FOR $(25 \mu \mathrm{M})$ treatment; and vi) CIS + FOR-H + siNrf2, siNrf2 transfection with CIS $(25 \mu \mathrm{M})$ and FOR $(25 \mu \mathrm{M})$ treatment. The concentrations of FOR and CIS to be used were selected as previously described (8).

MTT assay. The cells $\left(2 \times 10^{4}\right.$ cells/well) were plated in 96-well plates, and cell proliferation was determined using a MTT kit (cat. no. IM0280; Beijing Solarbio Science \& Technology Co., Ltd.). Briefly, following the corresponding treatments, MTT solution $(20 \mu \mathrm{l} ; 5 \mathrm{mM})$ was added to each well of the 96-well plates and incubated for a further $4 \mathrm{~h}$. The absorbance was measured at $570 \mathrm{~nm}$ using a microplate reader.

Flow cytometry assay. Apoptosis of the treated cells was measured by flow cytometry using an Annexin V-FITC Apoptosis Detection kit (cat. no. CA1020; Beijing Solarbio Science \& Technology Co., Ltd.). The collected cells were washed with cold sterile PBS, counted and resuspended in 1 $\mathrm{X}$ binding buffer, then incubated with Annexin V-FITC and propidium iodide in the dark at room temperature for $15 \mathrm{~min}$. The cells were then further diluted using PBS to $500 \mu \mathrm{l}$, and cell apoptosis was evaluated using a flow cytometer and FlowJo software (version 7.6.1; FlowJo LLC).

Biochemical measurements of the cells. MDA, CAT enzymatic activity and the activity of MPO in HK-2 cells were measured using the same methods as described for tissues. The levels of TNF- $\alpha$ and IL-1 $\beta$ in HK-2 cells were measured by Human TNF- $\alpha$ ELISA kit (cat. no. SEKH-0047; Beijing Solarbio Science \& Technology Co., Ltd.) and Human IL-1 $\beta$ ELISA kit (cat. no. SEKH-0002; Beijing Solarbio Science \& Technology Co., Ltd.) according to the manufacturer's instructions.

Statistical analysis. The data are presented as the mean \pm standard deviation. All experiments were performed in triplicate. Statistical significance in the study was analyzed by one-way ANOVA followed by Tukey's post hoc test and Bonferroni's correction. $\mathrm{P}<0.05$ was considered to indicate a statistically significant difference. The analyses were performed using SPSS 17.0 software (SPSS, Inc.).

\section{Results}

FOR protects against CIS-induced nephrotoxicity in the rat model. As presented in Fig. 1A, epithelial cell swelling, vacuolar degeneration and massive necrosis in the proximal tubules 


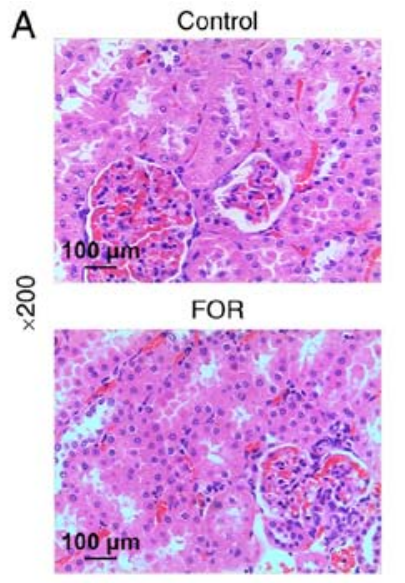

A

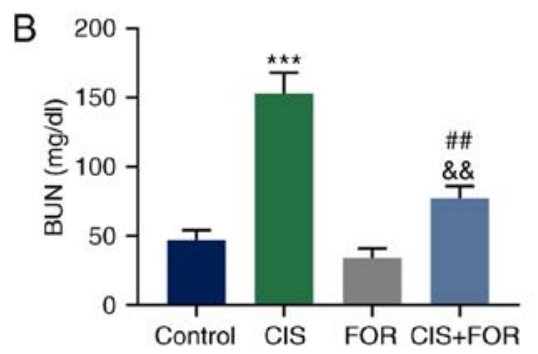

CIS

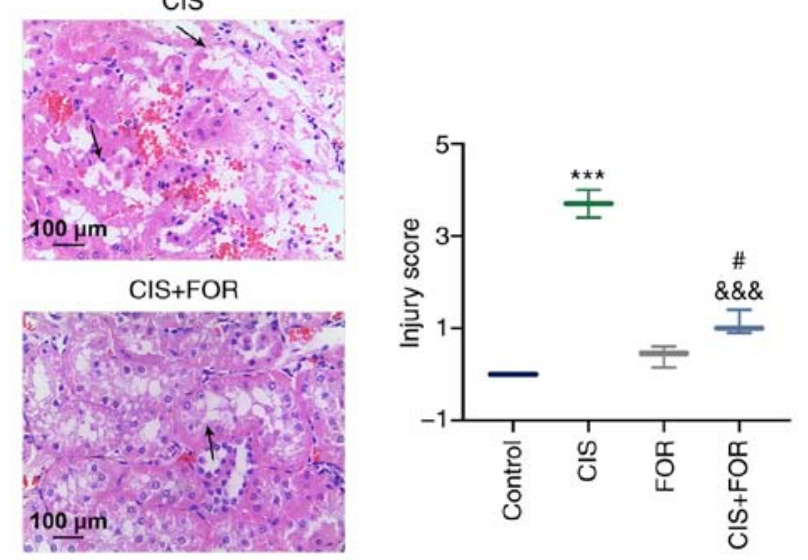

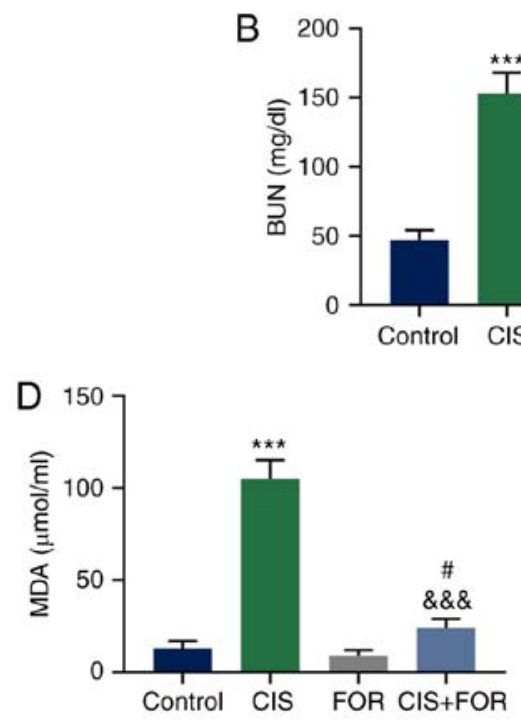
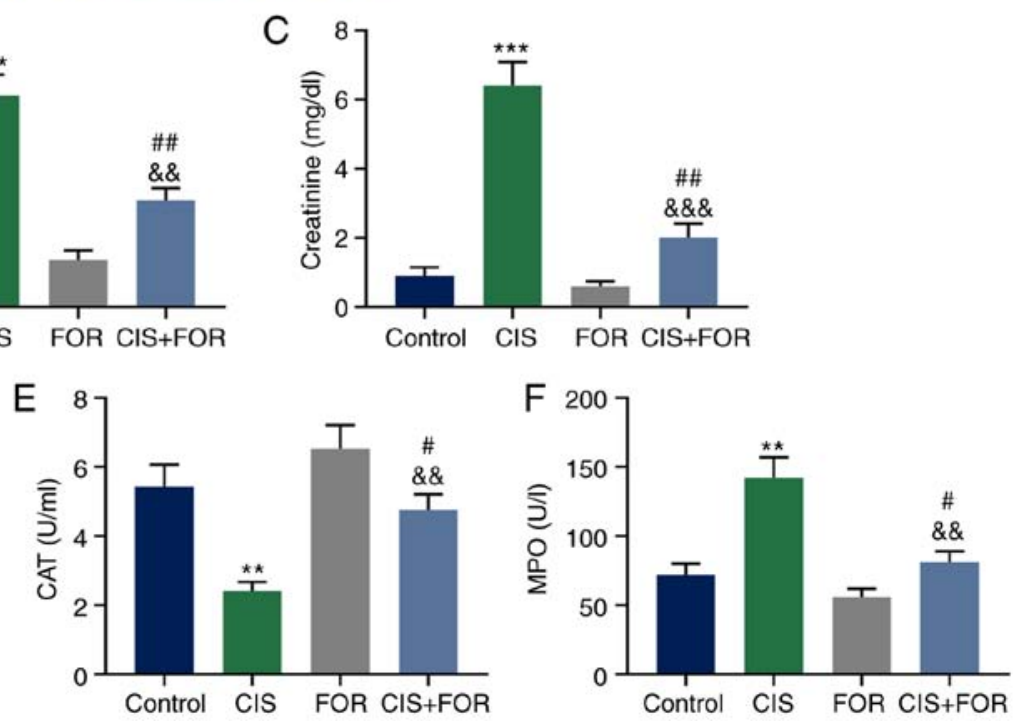

Figure 1. FOR ameliorates CIS-mediated acute kidney injury in a rat model. (A) Kidney histopathological examination was performed by hematoxylin and eosin staining in the rat model (magnification, x200). Arrows indicate areas of severe renal necrosis. The changes in (B) BUN and (C) creatinine levels in plasma, (D) MDA level, and (E) CAT and (F) MPO activities in kidney were ameliorated by FOR following treatment with CIS. Data are presented as mean \pm standard deviation. ${ }^{* *} \mathrm{P}<0.01,{ }^{* * *} \mathrm{P}<0.001$ vs. Control. ${ }^{\& \&} \mathrm{P}<0.01,{ }^{\& \& \&} \mathrm{P}<0.001$ vs. CIS. ${ }^{\# P} \mathrm{P}<0.05,{ }^{\# \#} \mathrm{P}<0.01$ vs. FOR. FOR, formononetin; CIS, cisplatin; BUN, blood urea nitrogen; MDA, malondialdehyde; MPO, myeloperoxidase; CAT, catalase.

were observed in rats treated by CIS, and these effects were not observed in the CIS + FOR treatment group. Furthermore, FOR treatment significantly reduced the CIS-increased injury score in renal tissues compared with the CIS group $(\mathrm{P}<0.00$; Fig. 1A).

The levels of BUN and creatinine in the plasma were significantly increased in the CIS group compared with the control group $(\mathrm{P}<0.001)$, but significantly reduced in the CIS + FOR group compared with the CIS group $(\mathrm{P}<0.001 ;$ Fig. 1B and $\mathrm{C}$ ).

The level of MDA in the rats was greatly increased by CIS treatment, but was significantly reduced in the CIS + FOR group $(\mathrm{P}<0.001$; Fig. 1D). Furthermore, the CAT activity was significantly reduced by CIS treatment, but significantly increased in the CIS + FOR group $(\mathrm{P}<0.01$; Fig. $1 \mathrm{E})$. The MPO activity of the rats was significantly increased by CIS treatment, and was significantly reduced by FOR treatment $(\mathrm{P}<0.01$; Fig. 1F). The levels of TNF- $\alpha$ (Fig. 2A; $\mathrm{P}<0.001)$ and IL-1 $\beta$ (Fig. $2 \mathrm{~B}, \mathrm{P}<0.001$ ) were significantly increased by treatment of rats with CIS $(\mathrm{P}<0.001)$, and were significantly decreased in the CIS + FOR group $(\mathrm{P}<0.001$; Fig. $2 \mathrm{~A}$ and $\mathrm{B})$.
FOR increases the expression levels of PPAR $\alpha, \mathrm{Nrf} 2, \mathrm{HO}-1$ and NQO1, which are reduced by CIS in the rat models. As presented in Fig. 2C and D, compared with the control group, CIS treatment significantly suppressed the mRNA and proteins levels of PPAR $\alpha, \mathrm{Nrf} 2, \mathrm{HO}-1$ and NQO1 in the rats $(\mathrm{P}<0.05)$, and these levels were significantly reversed by FOR treatment $(\mathrm{P}<0.001)$.

FOR protects $H K-2$ cells against CIS-induced injury in a PPAR $\alpha$-dependent manner. As presented in Fig. 3A, CIS treatment significantly suppressed proliferation of $\mathrm{HK}-2$ cells at $12(\mathrm{P}<0.05), 24(\mathrm{P}<0.01)$ and $48 \mathrm{~h}(\mathrm{P}<0.001)$ compared with the control group; however, this suppression was significantly reversed by FOR-L treatment at $48 \mathrm{~h}(\mathrm{P}<0.05)$ and by FOR-H treatment at $24(\mathrm{P}<0.05)$ and $48 \mathrm{~h}(\mathrm{P}<0.001)$. Notably, the promotive effect of FOR-H at 24 and $48 \mathrm{~h}$ on cell proliferation was significantly prevented by GW6471 treatment at $48 \mathrm{~h}$ $(\mathrm{P}<0.001)$.

As presented in Fig. 3B, the cell apoptosis rate of HK-2 cells was significantly increased in the CIS group $(\mathrm{P}<0.001)$, but was reduced by FOR-L $(\mathrm{P}<0.01)$ and FOR-H $(\mathrm{P}<0.001)$ in 

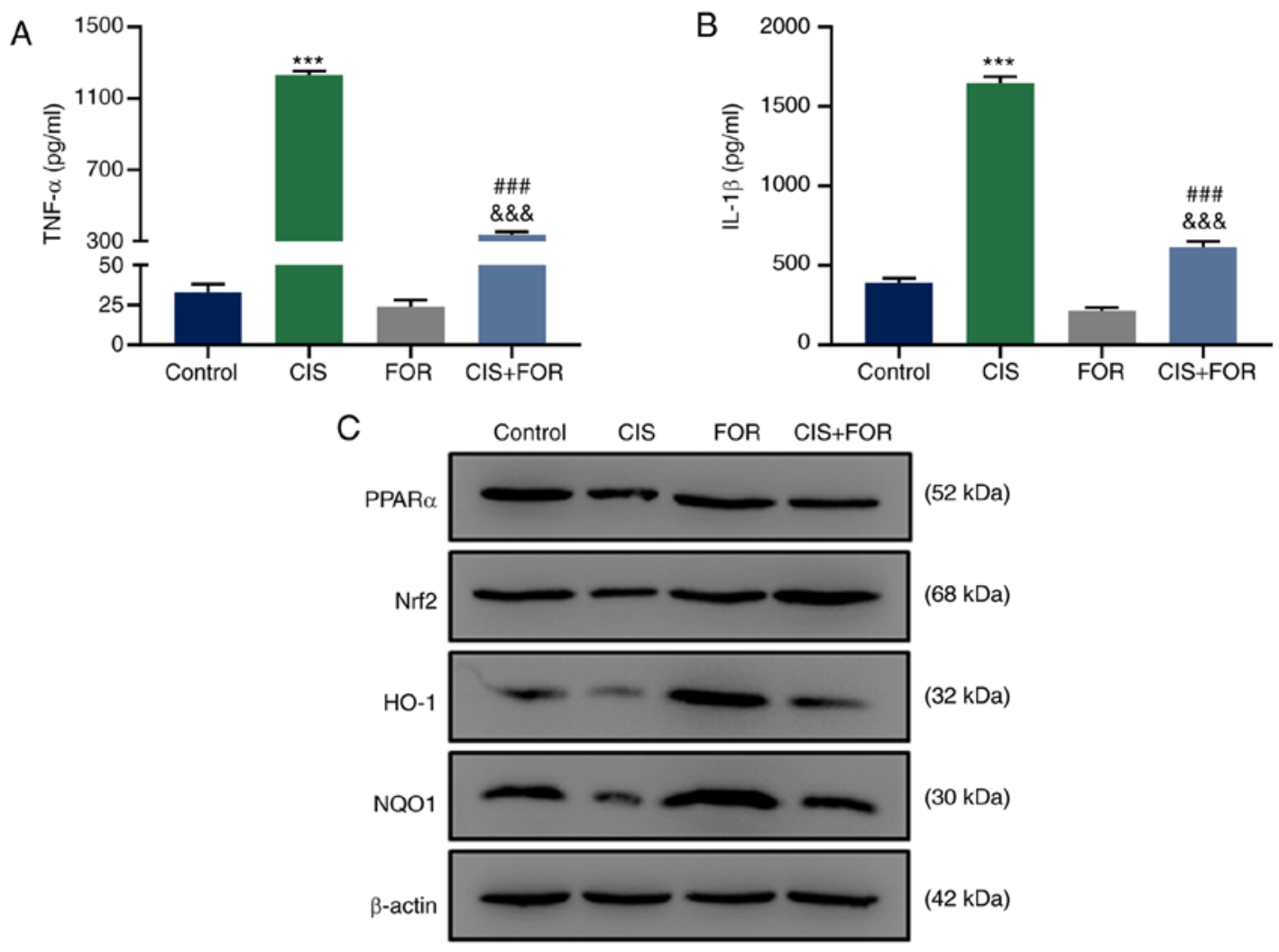

(52 kDa)

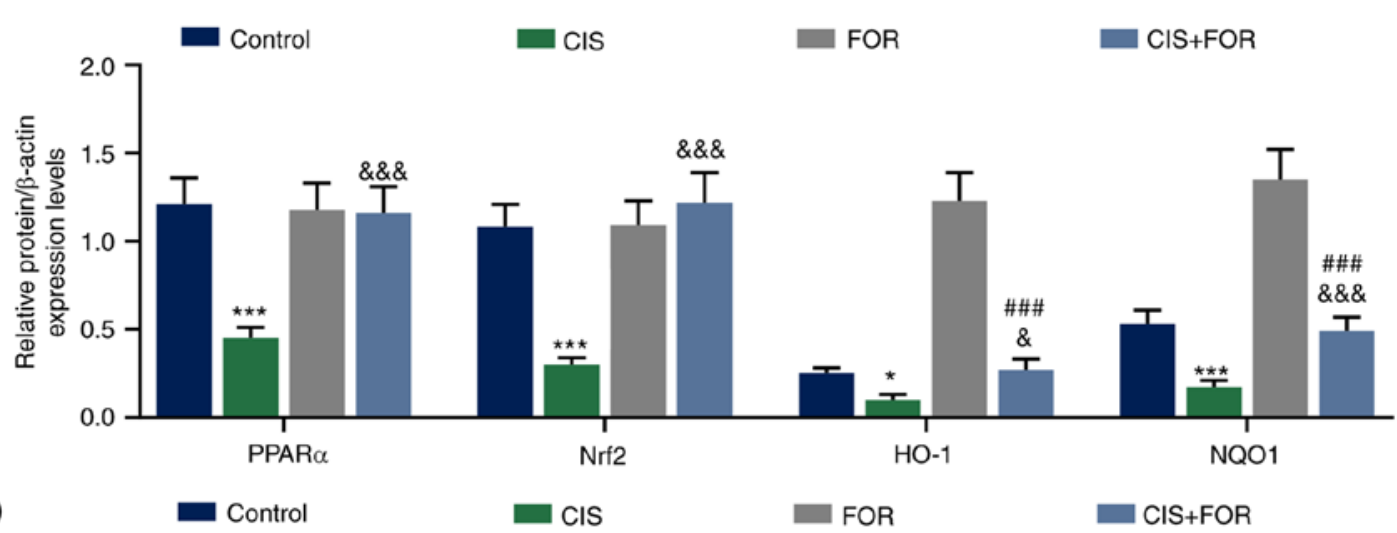

D

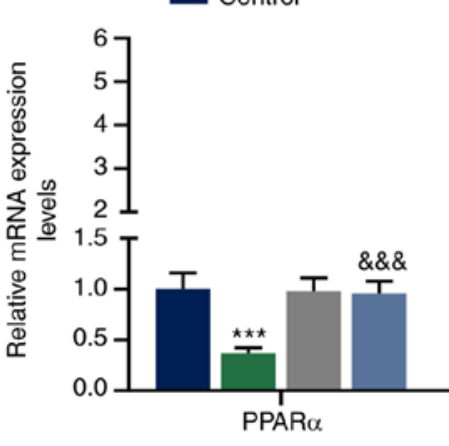

$\mathrm{CIS}$
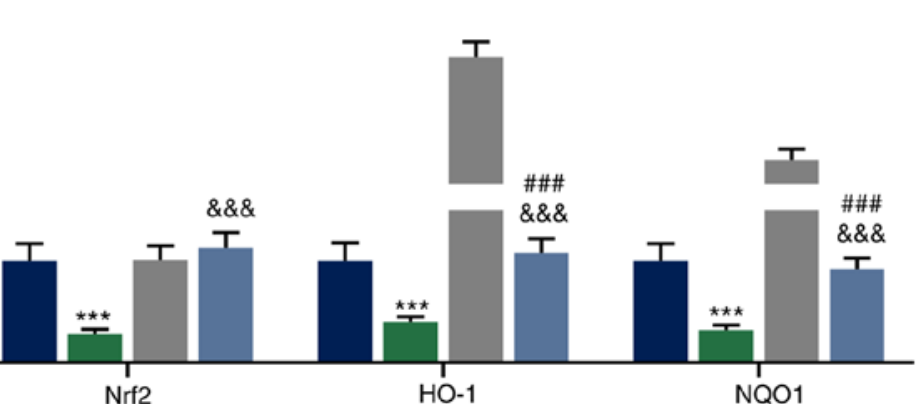

Figure 2. FOR increases CIS-reduced TNF- $\alpha$ and IL-1 $\beta$ levels and expressions of PPAR $\alpha$, Nrf2, HO-1 and NQO1 in the rat model. FOR increased CIS-reduced (A) TNF- $\alpha$ and (B) IL-1 $\beta$ levels. FOR increased the CIS-reduced (C) protein and (D) mRNA expression levels of PPAR $\alpha$, Nrf2, HO-1 and NQO1. Data are presented as mean \pm standard deviation. ${ }^{*} \mathrm{P}<0.05,{ }^{* * *} \mathrm{P}<0.001$ vs. Control. ${ }^{\&} \mathrm{P}<0.05$, \&\&\& $\mathrm{P}<0.001$ vs. CIS. ${ }^{\# \# \#} \mathrm{P}<0.001$ vs. FOR. FOR, formononetin; CIS, cisplatin; PPAR $\alpha$, peroxisome proliferator-activated receptor $\alpha$; Nrf2, nuclear factor erythroid 2-related factor 2; HO-1, heme oxygenase-1; NQO1, NAD(P)H quinone dehydrogenase 1 .

a dose-dependent manner. However, these effects of FOR-H were reversed by GW6471 treatment $(\mathrm{P}<0.001)$.

As presented in Fig. 3C, the MDA level in HK-2 cells was significantly increased in the CIS group $(\mathrm{P}<0.001)$, but was reduced by FOR-L $(\mathrm{P}<0.05)$ and FOR-H $(\mathrm{P}<0.01)$ in a dose-dependent manner. However, the effect of FOR-H on MDA level was significantly reversed by GW6471 treatment $(\mathrm{P}<0.01)$. As shown in Fig. 3D, CIS treatment significantly 
A
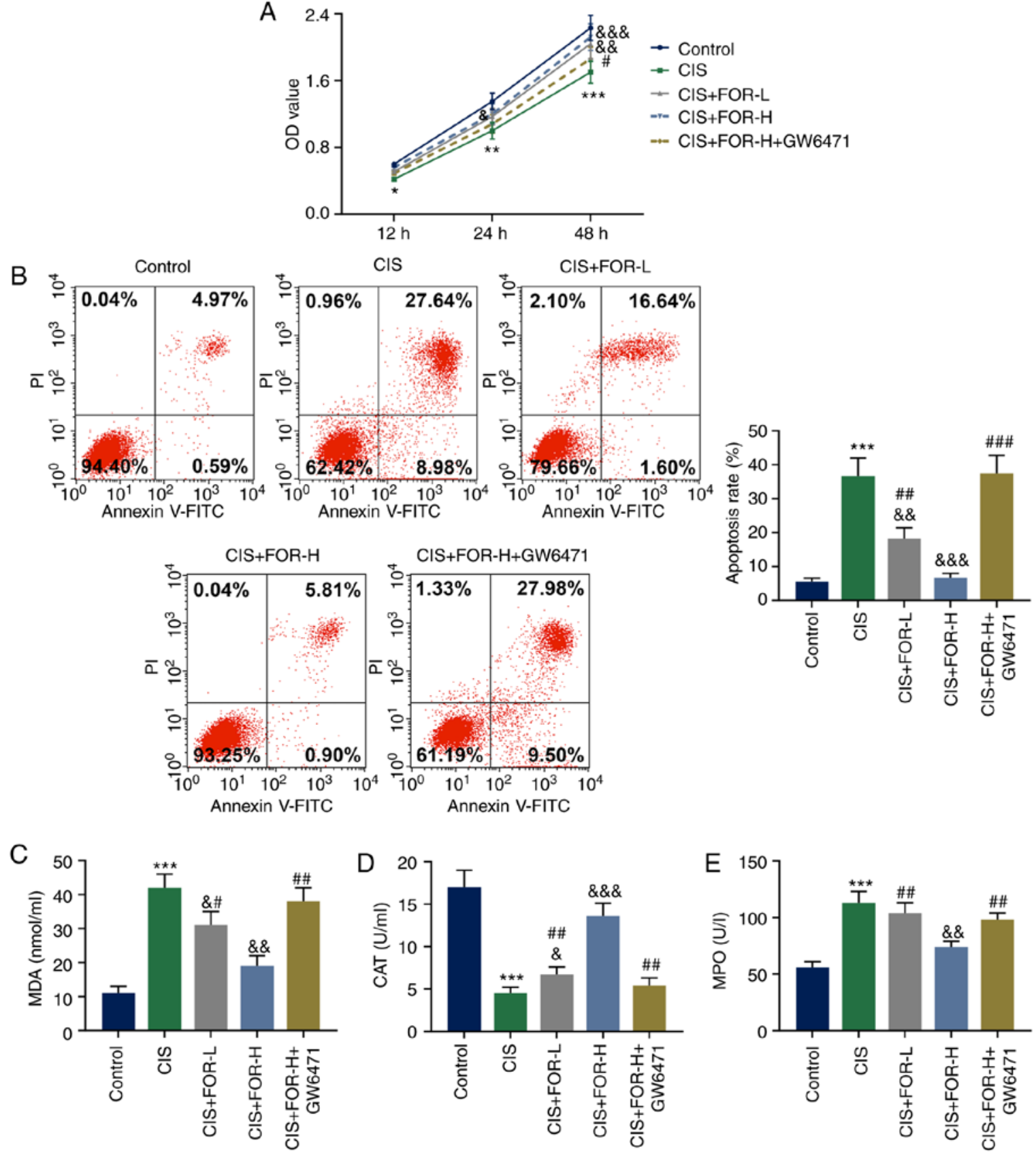

Figure 3. FOR protects against CIS-induced injury of HK-2 cells in a PPAR $\alpha$-dependent manner. (A) FOR increased the CIS-reduced proliferation in a PPAR $\alpha$-dependent manner. (B) FOR reduced the CIS-increased apoptosis in a PPAR $\alpha$-dependent manner. (C) FOR reduced the CIS-increased MDA level in a PPAR $\alpha$-dependent manner. FOR increased the CIS-reduced (D) CAT and (E) MPO activities in a PPAR $\alpha$-dependent manner. Data are presented as

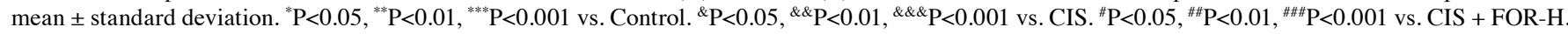
FOR, formononetin; CIS, cisplatin; PPAR $\alpha$, peroxisome proliferator-activated receptor $\alpha$; MDA, malondialdehyde; MPO, myeloperoxidase; CAT, catalase; PI, propidium iodide; $\mathrm{OD}$, optical density; L, low dose; $\mathrm{H}$, high dose.

suppressed CAT activity in $\mathrm{HK}-2$ cells $(\mathrm{P}<0.001)$, which was significantly reversed by FOR-L $(\mathrm{P}<0.05)$ and FOR-H $(\mathrm{P}<0.01)$ treatment in a dose-dependent manner, and this effect of FOR-H was reversed by GW6471 treatment $(\mathrm{P}<0.01)$. As presented in Fig. 3E, CIS treatment significantly enhanced the MPO activity in HK-2 cells $(\mathrm{P}<0.001)$, which was significantly reduced by FOR-H treatment $(\mathrm{P}<0.01)$, and GW6471 treatment significantly reversed this effect of FOR-H $(\mathrm{P}<0.01)$.

As shown in Fig. 4A and B, CIS treatment significantly increased the levels of TNF- $\alpha(\mathrm{P}<0.001)$ and IL-1 $\beta(\mathrm{P}<0.001)$ in $\mathrm{HK}-2$ cells, which were reversed by FOR-L $(\mathrm{P}<0.01)$ and
FOR-H $(\mathrm{P}<0.001)$. However, GW6471 treatment significantly reversed this effect of FOR-H $(\mathrm{P}<0.001)$.

FOR increases the expression levels of PPAR $\alpha, N r f 2, H O-1$ and NQO1, which are inhibited by CIS, in PPAR $\alpha$-dependent manner. As presented in Fig. 4C and D, CIS treatment significantly reduced the mRNA and proteins levels of PPAR $\alpha(\mathrm{P}<0.001), \mathrm{Nrf} 2$ $(\mathrm{P}<0.001)$, HO-1 $(\mathrm{P}<0.001)$ and NQO1 $(\mathrm{P}<0.001)$ in HK-2 cells, which was reversed by FOR-L $(\mathrm{P}<0.05)$ and FOR-H treatment $(\mathrm{P}<0.01)$. Furthermore, GW6471 treatment significantly reversed the effect of FOR-H of these expression levels $(\mathrm{P}<0.001)$. 

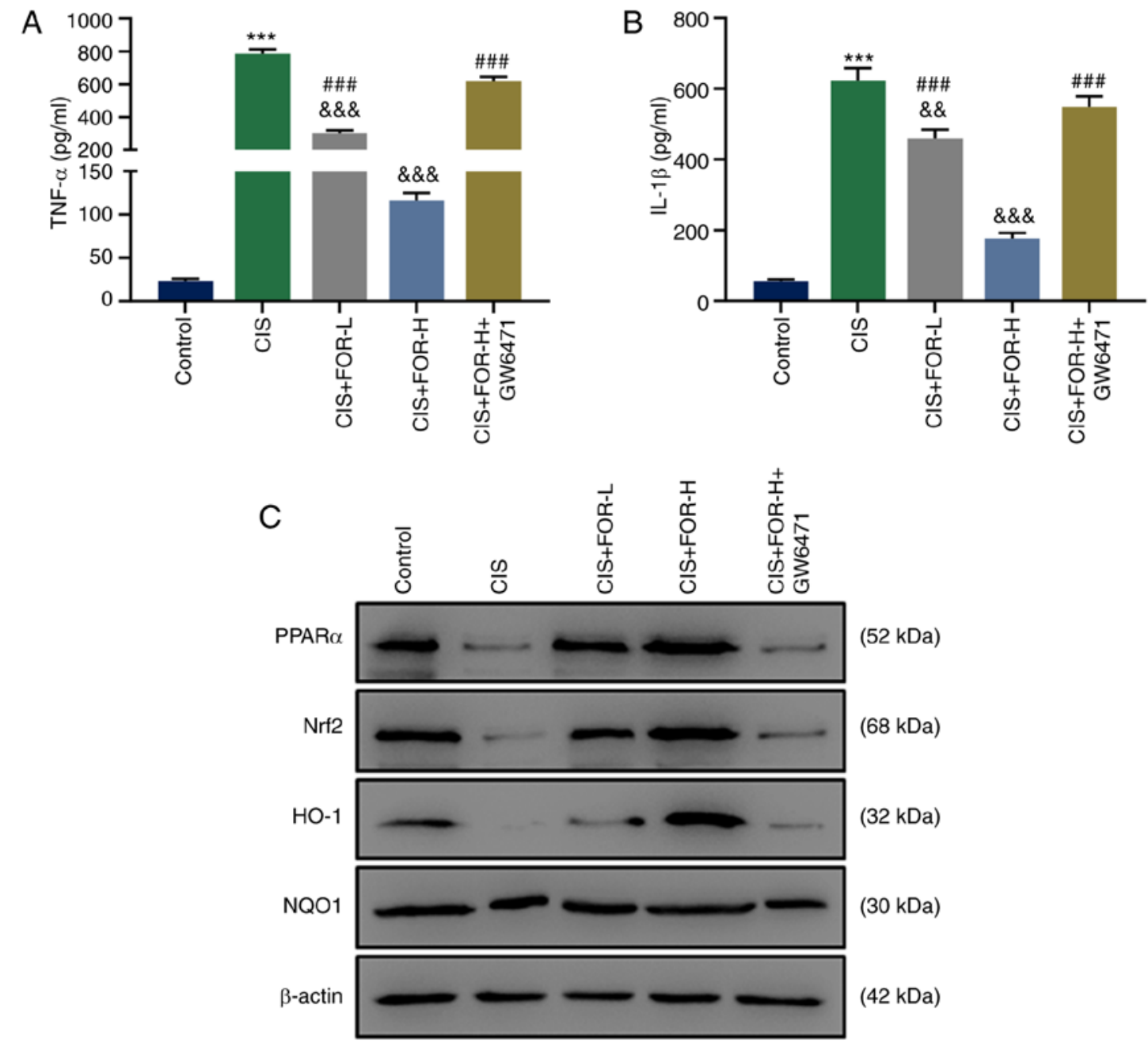

$(52 \mathrm{kDa})$

$(68 \mathrm{kDa})$

$(32 \mathrm{kDa})$

$(30 \mathrm{kDa})$

$(42 \mathrm{kDa})$
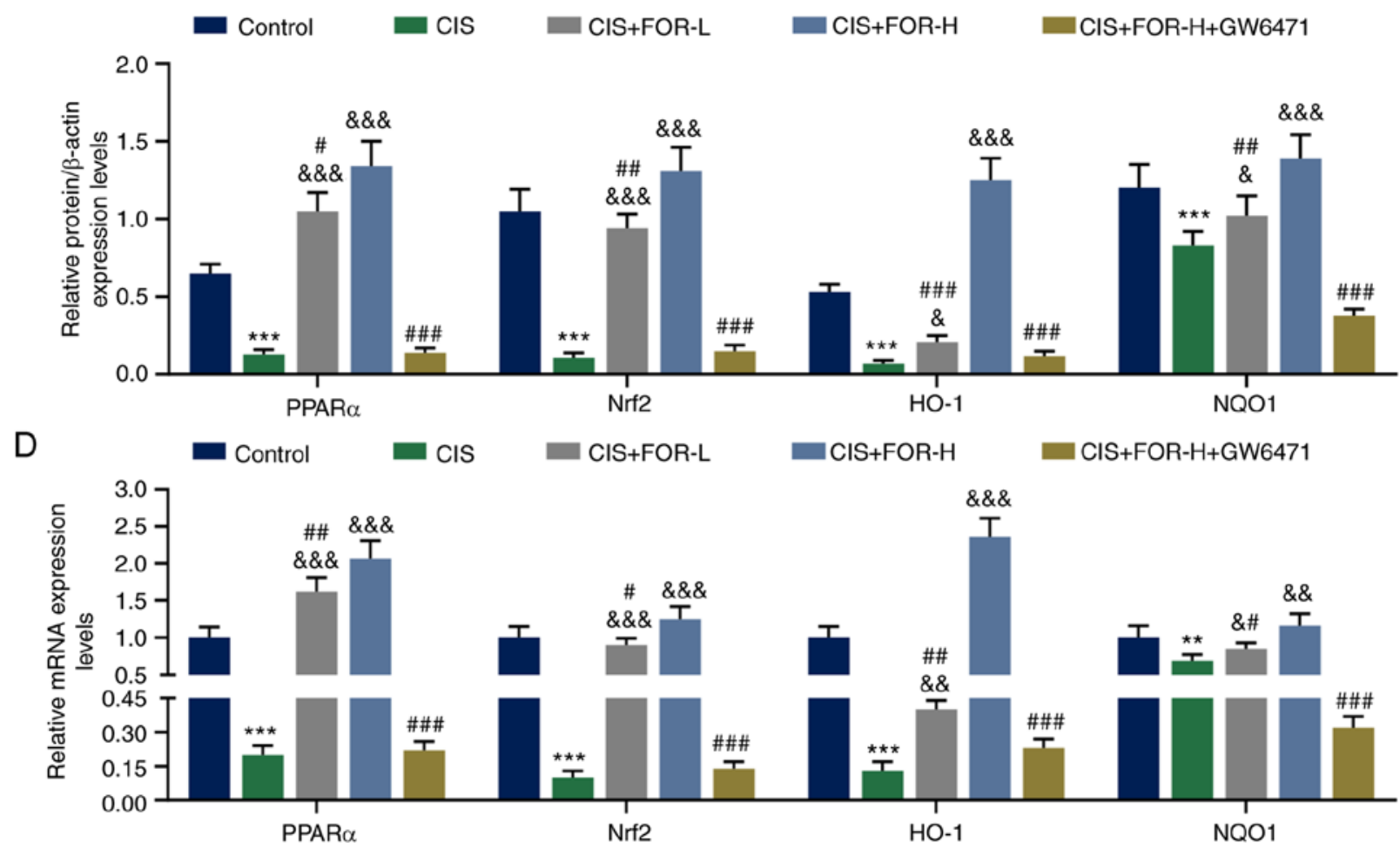

Figure 4. FOR protects against CIS-induced injury and expression levels of PPAR $\alpha$, Nrf2, HO-1 and NQO1 in HK-2 cells in a PPAR $\alpha$-dependent manner. FOR reduced the CIS-increased (A) TNF- $\alpha$ and (B) IL-1 $\beta$ levels in a PPAR $\alpha$-dependent manner. FOR increased the CIS-reduced (C) protein and (D) mRNA levels of PPAR $\alpha$, Nrf2, HO-1 and NQO1 in a PPAR $\alpha$-dependent manner. Data are presented as mean \pm standard deviation. ${ }^{* *} \mathrm{P}<0.01,{ }^{* * * *} \mathrm{P}<0.001$ vs. Control. ${ }^{\circledR} \mathrm{P}<0.05$,

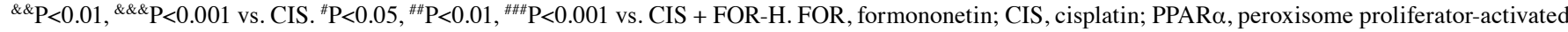
receptor $\alpha$; Nrf2, nuclear factor erythroid 2-related factor 2; HO-1, heme oxygenase-1; NQO1, NAD(P)H quinone dehydrogenase 1; L, low dose; H, high dose. 

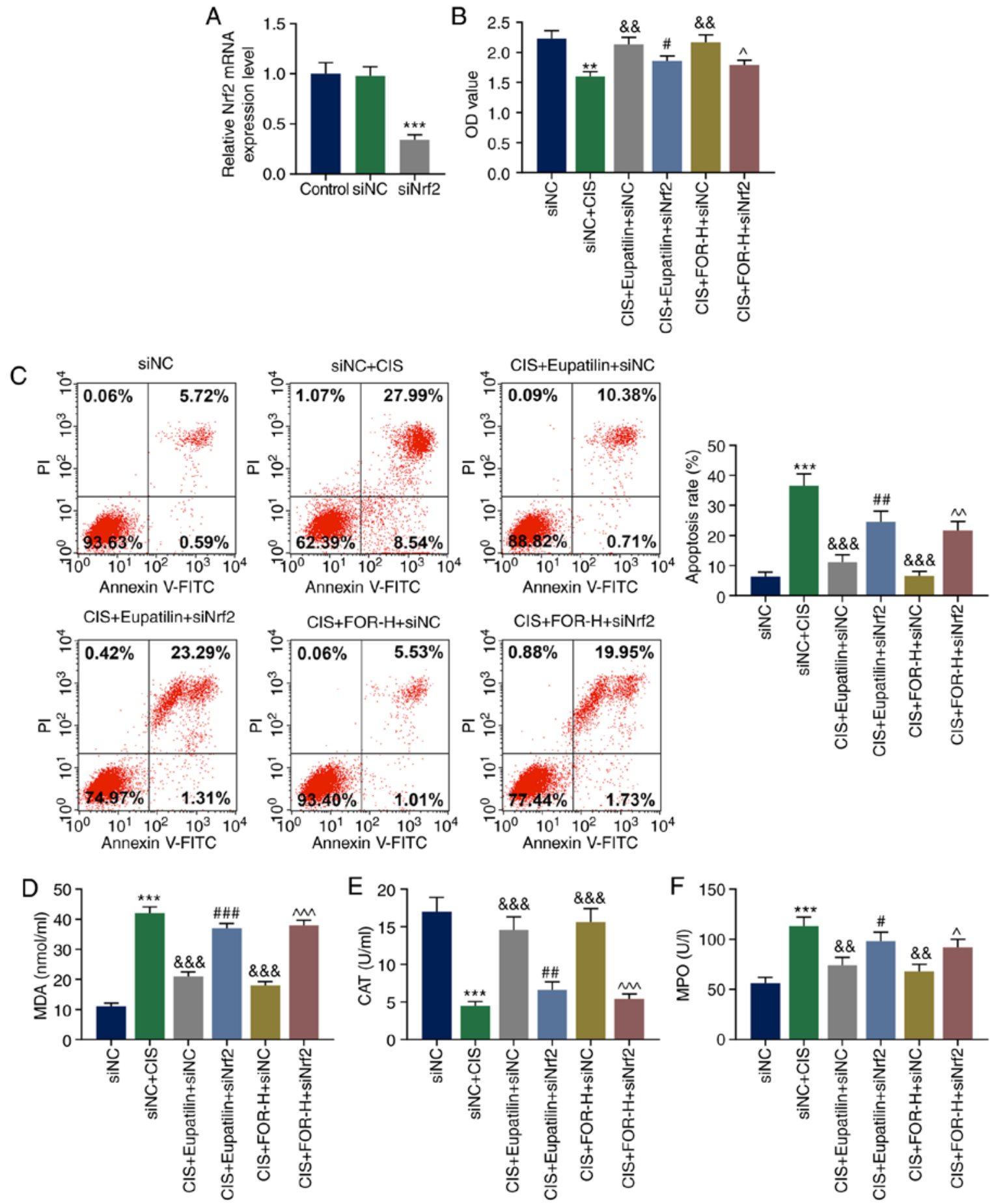

Figure 5. Nrf2 silencing effectively reverses the protective effect of eupatilin or FOR on CIS-induced injury of HK-2 cells. (A) Nrf2 mRNA expression was significantly downregulated in HK-2 cells by transfection with siNrf2. (B) Eupatilin or FOR increased the CIS-reduced proliferation in a Nrf2-dependent manner. (C) Eupatilin or FOR reduced the CIS-increased apoptosis in a Nrf2-dependent manner. (D) Eupatilin or FOR reduced the CIS-increased MDA level in a Nrf2-dependent manner. Eupatilin or FOR increased the CIS-reduced (E) CAT and (F) MPO activities in a Nrf2-dependent manner. Data are presented as mean \pm standard deviation. ${ }^{* *} \mathrm{P}<0.01,{ }^{* * * *} \mathrm{P}<0.001$ vs. siNC. ${ }^{\&} \mathrm{P}<0.01$, ${ }^{\text {\&\& }} \mathrm{P}<0.001$ vs. siNC $+\mathrm{CIS}$. ${ }^{\#} \mathrm{P}<0.05,{ }^{\# \#} \mathrm{P}<0.01,{ }^{\# \# *} \mathrm{P}<0.001$ vs. CIS + Eupatilin + siNC. ${ }^{\wedge} \mathrm{P}<0.05,{ }^{\wedge \wedge} \mathrm{P}<0.01,{ }^{\wedge \wedge} \mathrm{P}<0.001$ vs. CIS + FOR-H + siNC. Nrf2, nuclear factor erythroid 2-related factor 2; FOR, formononetin; CIS, cisplatin; MDA, malondialdehyde; MPO, myeloperoxidase; CAT, catalase; PI, propidium iodide; OD, optical density; H, high dose; si, small interfering RNA; NC, negative control.

Nrf2 silencing effectively reverses the protective effect of eupatilin or FOR on CIS-induced injury of HK-2 cells. Following transfection with siNrf2, the Nrf2 mRNA expression was significantly downregulated in siNrf2 cells $(\mathrm{P}<0.001$; Fig. 5A). As shown in Fig. 5B and C, the CIS-inhibited decrease in viability and increase in apoptosis of HK-2 cells were greatly attenuated by eupatilin $(\mathrm{P}<0.01)$ or FOR treatment $(\mathrm{P}<0.01)$, but significantly reversed by Nrf2 silencing $(\mathrm{P}<0.05)$. As presented in Fig. 5D-F, eupatilin $(\mathrm{P}<0.01)$ or FOR treatment $(\mathrm{P}<0.01)$ significantly attenuated the CIS-promoted MDA level and MPO activity, and the CIS-suppressed CAT activity. However, these effects were reversed by Nrf2 silencing $(\mathrm{P}<0.05)$. As shown in Fig. 6A and B, eupatilin $(\mathrm{P}<0.001)$ or FOR treatment $(\mathrm{P}<0.001)$ significantly attenuated the 

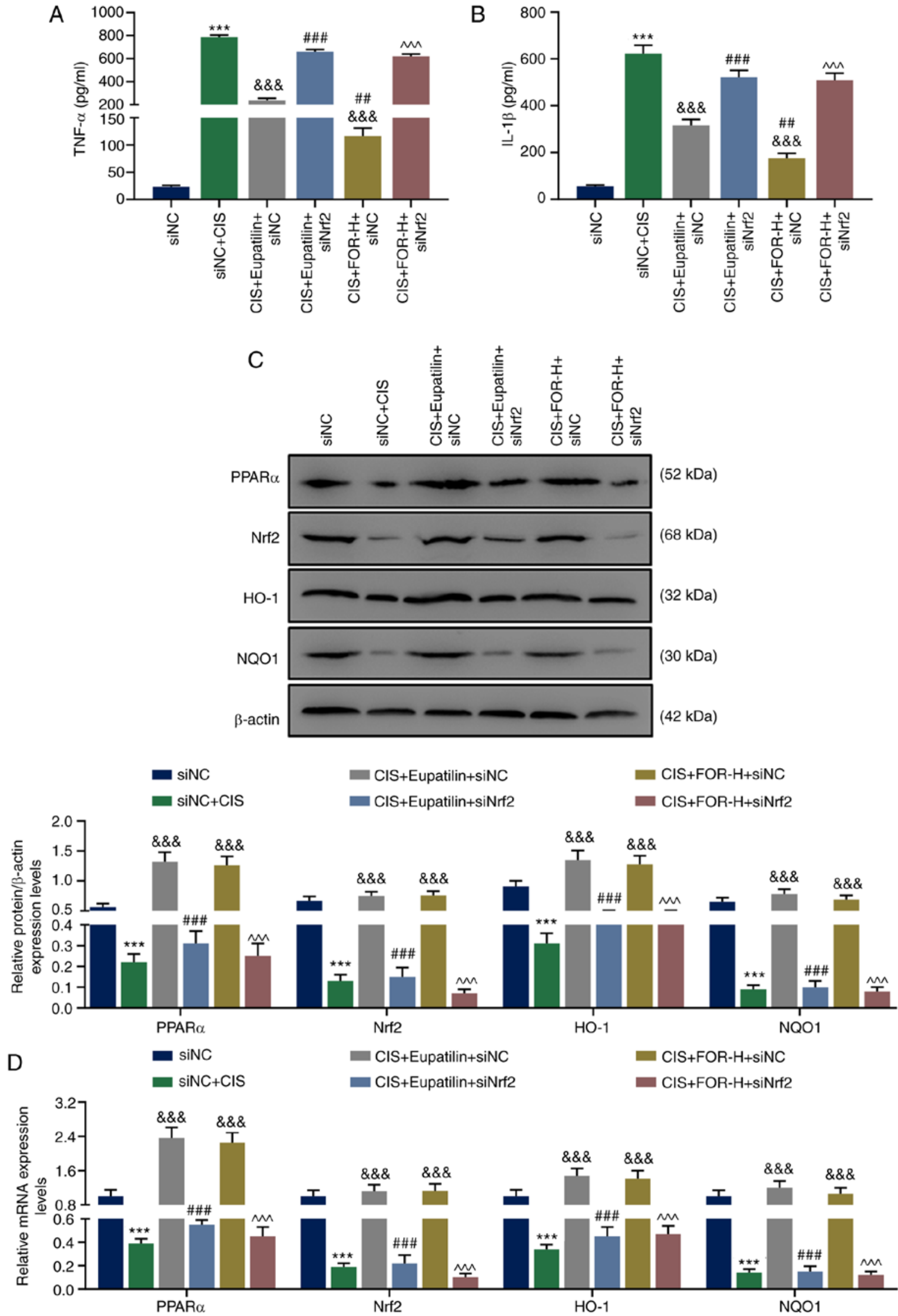

Figure 6. Nrf2 silencing effectively reverses the protective effect of eupatilin or FOR CIS-induced injury of HK-2 cells, and reverses the stimulative effect of eupatilin or FOR on the CIS-inhibited PPAR $\alpha / \mathrm{Nrf2} / \mathrm{HO}-1 / \mathrm{NQO} 1$ pathway in HK-2 cells. Eupatilin or FOR reduced the CIS-induced increases of (A) TNF- $\alpha$ and (B) IL-1 $\beta$ levels in a Nrf2-dependent manner. Eupatilin or FOR increased the CIS-induced reduced (C) protein and (D) mRNA expression levels of PPAR $\alpha$, $\mathrm{Nrf} 2, \mathrm{HO}-1$ and NQO1 in a Nrf2-dependent manner. Data are presented as mean \pm standard deviation. ${ }^{* * * *} \mathrm{P}<0.001$ vs. siNC. ${ }^{\& \& \&} \mathrm{P}<0.001 \mathrm{vs}$. siNC $+\mathrm{CIS}$ ${ }^{\# \#} \mathrm{P}<0.01,{ }^{\# \# \#} \mathrm{P}<0.001$ vs. CIS + Eupatilin + siNC. ${ }^{\wedge \wedge} \mathrm{P}<0.001$ vs. CIS + FOR-H + siNC. Nrf2, nuclear factor erythroid 2-related factor 2; FOR, formononetin; CIS, cisplatin; $\mathrm{H}$, high dose; si, small interfering RNA; NC, negative control; PPAR $\alpha$, peroxisome proliferator-activated receptor $\alpha$; Nrf2, nuclear factor erythroid 2-related factor 2; HO-1, heme oxygenase-1; NQO1, NAD(P)H quinone dehydrogenase 1. 
CIS-increased TNF- $\alpha$ and IL-1 $\beta$ levels, which were reversed by $\mathrm{Nrf} 2$ silencing $(\mathrm{P}<0.001)$.

Nrf2 silencing effectively reverses the stimulatory effect of eupatilin or FOR on the CIS-inhibited PPAR /Nrf2/HO-1/ NQO1 pathway in HK-2 cells. As presented in Fig. $6 \mathrm{C}$ and D, eupatilin $(\mathrm{P}<0.001)$ and FOR treatment $(\mathrm{P}<0.001)$ significantly increased the mRNA and proteins levels of PPAR $\alpha$, Nrf2, HO-1 and NQO1 of HK-2 cells, which were previously reduced by CIS; however, this was reversed by Nrf2 silencing $(\mathrm{P}<0.001)$.

\section{Discussion}

The level of CIS in the kidney is the highest in the proximal tubule (28). Proximal tubular cell injury and death are responsible for CIS-induced AKI (29), and proximal tubular cell death is associated with high morbidity and mortality (30). Therefore, in order to relieve kidney injury of patients with AKI and investigate the protective effect of FOR on CIS-induced AKI, the present study examined kidney and proximal tubular cells under CIS condition. The present study found that FOR protected against CIS-induced nephrotoxicity, as supported by improved renal function, attenuated histopathological changes of the rat model, and improved cell viability, reduced apoptosis, oxidative stress, and inflammatory reaction of renal proximal tubular cells.

PPAR $\alpha$ protects against metabolic and inflammatory derangements associated with AKI (31). Therefore, GW6471 (a selective PPAR $\alpha$ antagonist) was used to treat renal proximal tubular cells to investigate the effect of PPAR $\alpha$ on FOR in preventing HK-2 cells from CIS-induced injury. The results demonstrated that FOR protected against CIS-induced injury of HK-2 cells and increased the expression levels of PPAR $\alpha$, Nrf2, HO-1 and NQO1, which were previously reduced by CIS, in a PPAR- $\alpha$-dependent manner.

In response to natural Nrf2 activators, oxidative stress, inflammation and kidney disease are induced in animal models, while Nrf2 silencing amplifies these pathogenic pathways (32). Zoja et al (33) also reported that blocking Nrf2-activation promotes oxidative stress, inflammation and the development of tissue damage in the kidney. Targeting Nrf2 ameliorates oxidative stress and inflammatory reactions in kidney disease (34). Furthermore, FOR upregulates Nrf2 in vivo and in vitro to protect against AKI (18). The role of Nrf2 in FOR protecting HK-2 cells from CIS-induced injury was further investigated, and it was identified that FOR treatment or upregulated PPAR- $\alpha$ protected HK-2 cells against CIS-induced injury in an Nrf2-dependent manner, indicating that FOR treatment protects HK-2 cells against renal injury induced by CIS through activation of the PPAR $\alpha / \mathrm{Nrf} 2$ pathway.

Aladaileh et al (35) reported that FOR upregulates Nrf2/HO-1 signaling to prevent oxidative stress, inflammatory reaction and kidney impairment in methotrexate-induced rats. Upregulated Nrf2/ARE/HO-1 signaling suppresses oxidative stress, inflammatory reactions and apoptosis in rat kidneys exposed to cyclophosphamide (36). Gang et al (37) indicated that NQO1 protects cells against renal failure induced by CIS. The present study demonstrated that the PPAR $\alpha$, Nrf2, HO-1 and NQO1 expression levels previously reduced by CIS were reversed by FOR or upregulated PPAR- $\alpha$ in an Nrf2-dependent manner. Therefore, FOR treatment protected HK-2 cells against CIS-induced renal injury through activation the of $\alpha / \mathrm{Nrf} 2 / \mathrm{HO}-1 / \mathrm{NQO} 1$ pathway.

The current findings demonstrated that the protective effects of FOR on CIS-induced AKI were associated with activation of the PPAR $\alpha-\mathrm{Nrf2}-\mathrm{HO}-1 / \mathrm{NQO} 1$ pathway. However, whether FOR could also clinically reduce the tumoricidal efficacy of CIS remains unclear; therefore, more experiments are needed to investigate the combined effects of FOR and CIS on patients with AKI and the associated molecular mechanisms. Additionally, other better alternative products, such as PPAR agonists, may be applied as first line therapy for AKI in future study. The present study focused both on cells and animals, supporting the results of each other. Certainly, studies could be conducted more deeply both in cells and animals in the future.

Taken together, the protective effect of FOR against CIS-induced AKI, and improvement of renal function and alleviation of histopathological changes were associated with the reduced oxidative stress, inflammatory reaction, and activation of the PPAR $\alpha-\mathrm{Nrf} 2-\mathrm{HO}-1 / \mathrm{NQO} 1$ pathway. The current research demonstrated that FOR is a promising drug for preventing CIS-injured AKI.

\section{Acknowledgements}

Not applicable.

\section{Funding}

No funding was received.

\section{Availability of data and materials}

The datasets used and/or analyzed during the current study are available from the corresponding author on reasonable request.

\section{Authors' contributions}

YH and JM substantially contributed to the conception and design of the study. WL, LP, YC and QZ acquired, analyzed and interpreted the data. YH and JM drafted the article and critically revised it for important intellectual content. YH agreed to be accountable for all aspects of the work in ensuring that questions related to the accuracy or integrity of the work are appropriately investigated and resolved. All authors read and approved the final manuscript.

\section{Ethics approval and consent to participate}

This study was approved by the Ethical Committee of Experimental Animals of Zigong First People's Hospital, Zigong, China (approval no. ZFPH201904223).

\section{Patient consent for publication}

Not applicable.

\section{Competing interests}

The authors declare that they have no competing interests. 


\section{References}

1. Lee YJ, Chan JP, Hsu WL, Lin KW and Chang CC: Prognostic factors and a prognostic index for cats with acute kidney injury. J Vet Intern Med 26: 500-505, 2012.

2. Farrar A: Acute kidney injury. Nurs Clin North Am 53: 499-510, 2018.

3. Brix S and Stahl R: Acute kidney injury. Dtsch Med Wochenschr 142: 290-300, 2017 (In German).

4. Ni J, Hou X, Wang X, Shi Y, Xu L, Zheng X, Liu N, Qiu A and Zhuang S: 3-deazaneplanocin A protects against cisplatin-induced renal tubular cell apoptosis and acute kidney injury by restoration of E-cadherin expression. Cell Death Dis 10: 355 , 2019.

5. de Almeida CDC, Simões E Silva AC, de Queiroz Oliveira JA, Batista ISF, Pereira FH, Gonçalves JE, Nobre V and Martins MAP: Vancomycin-associated nephrotoxicity in non-critically ill patients admitted in a Brazilian public hospital: A prospective cohort study. PLoS One 14: e0222095, 2019.

6. Lameire NH, Bagga A, Cruz D, De Maeseneer J, Endre Z, Kellum JA, Liu KD, Mehta RL, Pannu N, Van Biesen W and Vanholder R: Acute kidney injury: An increasing global concern. Lancet 382: 170-179, 2013.

7. Rashid S, Nafees S, Siddiqi A, Vafa A, Afzal SM, Parveen R, Ali N, Hasan SK, Barnwal P, Shahid A and Sultana S: Partial protection by $18 \beta$ glycrrhetinic acid against cisplatin induced oxidative intestinal damage in wistar rats: Possible role of NFkB and caspases. Pharmacol Rep 69: 1007-1013, 2017.

8. Lee H, Lee D, Kang KS, Song JH and Choi YK: Inhibition of intracellular ROS accumulation by formononetin attenuates cisplatin-mediated apoptosis in LLC-PK1 cells. Int J Mol Sci 19 813,2018

9. Li J, Jiang K, Qiu X, Li M, Hao Q, Wei L, Zhang W, Chen B and Xin X: Overexpression of CXCR4 is significantly associated with cisplatin-based chemotherapy resistance and can be a prognostic factor in epithelial ovarian cancer. BMB Rep 47: 33-38, 2014.

10. Park JY, Lee D, Jang HJ, Jang DS, Kwon HC, Kim KH, Kim SN, Hwang GS, Kang KS and Eom DW: Protective effect of artemisia asiatica extract and its active compound eupatilin against cisplatin-induced renal damage. Evid Based Complement Alternat Med 2015: 483980, 2015.

11. Zhang YZ,Zhang J, Tan L, Xia Z, Wang CZ, Zhou LD, Zhang Q and Yuan CS: Preparation and evaluation of temperature and magnetic dual-responsive molecularly imprinted polymers for the specific enrichment of formononetin. J Sep Sci 41: 3060-3068, 2018.

12. Huang D, Wang C, Duan Y, Meng Q, Liu Z, Huo X, Sun H, Ma X and Liu K: Targeting Oct2 and P53: Formononetin prevents cisplatin-induced acute kidney injury. Toxicol Appl Pharmacol 326: 15-24, 2017.

13. Chtourou Y, Aouey B, Aroui S, Kebieche M and Fetoui H: Anti-apoptotic and anti-inflammatory effects of naringin on cisplatin-induced renal injury in the rat. Chem Biol Interact 243: 1-9, 2016.

14. Ning C, Gao X, Wang C, Huo X, Liu Z, Sun H, Yang X, Sun P, Ma X, Meng Q and Liu K: Protective effects of ginsenoside Rg1 against lipopolysaccharide/d-galactosamine-induced acute liver injury in mice through inhibiting toll-like receptor 4 signaling pathway. Int Immunopharmacol 61: 266-276, 2018.

15. Hwang JS, Kang ES, Han SG, Lim DS, Paek KS, Lee CH and Seo HG: Formononetin inhibits lipopolysaccharide-induced release of high mobility group box 1 by upregulating SIRT1 in a PPARס-dependent manner. PeerJ 6: e4208, 2018.

16. Mu H, Bai YH, Wang ST, Zhu ZM and Zhang YW: Research on antioxidant effects and estrogenic effect of formononetin from Trifolium pratense (red clover). Phytomedicine 16: 314-319, 2009.

17. Nguyen LTH, Nguyen UT, Kim YH, Shin HM and Yang IJ: Astragali Radix and its compound formononetin ameliorate diesel particulate matter-induced skin barrier disruption by regulation of keratinocyte proliferation and apoptosis. J Ethnopharmacol 228: 132-141, 2019.

18. Huang D, Wang C, Meng Q, Liu Z, Huo X, Sun H, Yang S, Ma X, Peng $\mathbf{J}$ and Liu K: Protective effects of formononetin against rhabdomyolysis-induced acute kidney injury by upregulating NRF2 in vivo and in vitro. RSC Adv 6: 110874-110883, 2016.

19. Gonzalez-Manan D, D'Espessailles A, Dossi CG, San Martin M, Mancilla RA and Tapia GS: Rosa mosqueta oil prevents oxidative stress and inflammation through the upregulation of PPAR- $\alpha$ and NRF2 in C57BL/6J mice fed a high-fat diet. J Nutr 147: 579-588, 2017.
20. Wang WR, Liu EQ, Zhang JY, Li YX, Yang XF, He YH, Zhang W, Jing $T$ and Lin R: Activation of PPAR alpha by fenofibrate inhibits apoptosis in vascular adventitial fibroblasts partly through SIRT1-mediated deacetylation of FoxO1. Exp Cell Res 338: 54-63, 2015.

21. Yang S, Wei L, Xia R, Liu L, Chen Y, Zhang W, Li Q, Feng K, Yu M, Zhang W, et al: Formononetin ameliorates cholestasis by regulating hepatic SIRT1 and PPAR $\alpha$. Biochem Biophys Res Commun 512: 770-778, 2019.

22. Shen J, Rasmussen M, Dong QR, Tepel M and Scholze A Expression of the NRF2 target gene NQO1 is enhanced in mononuclear cells in human chronic kidney disease. Oxid Med Cell Longev 2017: 9091879, 2017.

23. Cao SS, Yan M, Hou ZY, Chen Y, Jiang YS, Fan XR, Fang PF and Zhang BK: Danshen modulates Nrf2-mediated signaling pathway in cisplatin-induced renal injury. J Huazhong Univ Sci Technolog Med Sci 37: 761-765, 2017.

24. Shelton LM, Park BK and Copple IM: Role of Nrf2 in protection against acute kidney injury. Kidney Int 84: 1090-1095, 2013.

25. Ansari MA: Sinapic acid modulates Nrf2/HO-1 signaling pathway in cisplatin-induced nephrotoxicity in rats. Biomed Pharmacother 93: 646-653, 2017.

26. Shen Y, Qiu T, Liu XH, Zhang L, Wang ZS and Zhou JQ: Renal ischemia-reperfusion injury attenuated by splenic ischemic preconditioning. Eur Rev Med Pharmacol Sci 22: 2134-2142, 2018.

27. Livak KJ and Schmittgen TD: Analysis of relative gene expression data using real-time quantitative PCR and the 2(-Delta Delta C(T)) method. Method 25: 402-408, 2001

28. Camano S, Lazaro A, Moreno-Gordaliza E, Torres AM, de Lucas C, Humanes B, Lazaro JA, Milagros Gomez-Gomez M, Bosca L and Tejedor A: Cilastatin attenuates cisplatin-induced proximal tubular cell damage. J Pharmacol Exp Ther 334: 419-429, 2010

29. Pabla N and Dong Z: Cisplatin nephrotoxicity: Mechanisms and renoprotective strategies. Kidney Int 73: 994-1007, 2008.

30. Coelho S, Cabral G, Lopes JA and Jacinto A: Renal regeneration after acute kidney injury. Nephrology (Carlton) 23: 805-814, 2018.

31. Iwaki T, Bennion BG, Stenson EK, Lynn JC, Otinga C, Djukovic D, Raftery D, Fei L, Wong HR, Liles WC and Standage SW: PPARa contributes to protection against metabolic and inflammatory derangements associated with acute kidney injury in experimental sepsis. Physiol Rep 7: e14078, 2019.

32. Kong W, Fu J, Liu N, Jiao C, Guo G, Luan J, Wang H, Yao L, Wang L, Yamamoto M, et al: Nrf2 deficiency promotes the progression from acute tubular damage to chronic renal fibrosis following unilateral ureteral obstruction. Nephrol Dial Transplant 33: 771-783, 2018

33. Zoja C, Benigni A and Remuzzi G: The Nrf2 pathway in the progression of renal disease. Nephrol Dial Transplant 29 (Suppl 1): i19-i24, 2014

34. Ruiz S, Pergola PE, Zager RA and Vaziri ND: Targeting the transcription factor Nrf2 to ameliorate oxidative stress and inflammation in chronic kidney disease. Kidney Int 83: 1029-1041, 2013

35. Aladaileh SH, Hussein OE, Abukhalil MH, Saghir SAM, Bin-Jumah M, Alfwuaires MA, Germoush MO, Almaiman AA and Mahmoud AM: Formononetin upregulates Nrf2/HO-1 signaling and prevents oxidative stress, inflammation, and kidney injury in methotrexate-induced rats. Antioxidants (Basel) 8: 430, 2019.

36. ALHaithloul HAS, Alotaibi MF, Bin-Jumah M, Elgebaly $\mathrm{H}$ and Mahmoud AM: Olea europaea leaf extract up-regulates Nrf2/ARE/HO-1 signaling and attenuates cyclophosphamide-induced oxidative stress, inflammation and apoptosis in rat kidney. Biomed Pharmacother 111: 676-685, 2019.

37. Gang GT, Kim YH, Noh JR, Kim KS, Jung JY, Shong M, Hwang JH and Lee CH: Protective role of NAD $(\mathrm{P}) \mathrm{H}$ :quinone oxidoreductase 1 (NQO1) in cisplatin-induced nephrotoxicity. Toxicol Lett 221: 165-175, 2013.

This work is licensed under a Creative Commons Attribution-NonCommercial-NoDerivatives 4.0 International (CC BY-NC-ND 4.0) License. 